\title{
Estudo longitudinal sobre portador são de Stapbylococcus aureus em alunos de um curso de auxiliar de enfermagem
}

\author{
Longitudinal study on healthy carrier of Stapbylococcus aureus \\ in students of a thecnical nursing course
}

Branca Maria de Oliveira Santos

\begin{abstract}
Resumo Este trabalho objetivou conhecer o grau de colonização pelo Staphylococcus aureus e a evolução do estado de portador são em alunos de um curso de Auxiliar de Enfermagem, durante a formação profissional. Participaram 42 alunos, dos quais foram colhidas amostras da cavidade nasal e mãos (direita e esquerda) em seis diferentes momentos da formação. Do total de alunos, 19 (45,2\%) comportaram-se como portadores ocasionais, $12(28,6 \%)$ como intermitentes, $6(14,3 \%)$ como persistentes e $5(11,9 \%)$ como não portadores, demonstrando que a colonização não aumentou com o decorrer do curso. Dos alunos, 24 (57,1\%) referiram não terem desenvolvido atividades relacionadas à enfermagem antes e/ou durante o curso e 18 (42,9\%) referiram exercê-las como atendentes.
\end{abstract}

Palavras-chaves: Portador são. Staphylococcus aureus. Estudo longitudinal.

\begin{abstract}
The objective of the present study was to determine the extent of colonization by Staphylococcus aureus and the evolution of carrier status among students of a Technical Nursing Course during their professional training. Forty students participated in the study; samples were collected from their nasal cavity and right and left hands at six different times during the thecnical nursing course. Nineteen students (45.2\%) were found to be accasional carriers, 12 (28.6\%) were intermittent carriers, $6(14.3 \%)$ were persistent carriers, and $5(11.9 \%)$ were non-carriers, showing that colonization did not increase during the course. Twenty four of them (57.1\%) did not perform activities related to nursing before or during the course, whereas 18 (42.9\%) performed them.
\end{abstract}

Key-words: Healthy Carriers. Staphylococcus aureus. Longitudinal study.

O portador são tem sido considerado a mais silenciosa, porém a mais perigosa fonte de microrganismos responsáveis por infecções, não havendo outra forma de reconhecê-lo que não mediante a adoção de métodos laboratoriais².

Distinguem-se entre eles os que nunca apresentaram os sintomas da doença (portadores passivos) e aqueles que já os apresentaram no passado ou poderão vir a tê-los no futuro (portadores ativos) 34.

Considerando que ambos os tipos albergam o agente infectante em seu organismo, embora apresentem-se destituídos de sintomatologia, o que se faz normalmente é usar denominações para distinguir os vários períodos de colonização pelo microrganismo. Assim, eles podem ser

Escola de Enfermagem de Ribeirão Preto, Universidade de São Paulo, Ribeirão Preto, SP, Brasil. Apoio financeiro: CNPq

Endereço para correspondência: Prof ${ }^{\underline{a}}$ Dr ${ }^{\text {a }}$ Branca Maria de Oliveira Santos. R. Imbuia 25, Jardim Recreio, 14040-200 Ribeirão Preto, SP, Brasil.

Fax: 5516 630-5454

Recebido para publicação em 19/1/98. 
classificados em portadores permanentes ou persistentes, quando apresentam capacidade de albergar o agente por longo tempo; portadores intermitentes ou transitórios, quando albergam o agente por períodos variáveis; portadores ocasionais, quando abrigam o agente infeccioso por curto tempo, com culturas negativas posteriormente e não portadores, quando não colonizados anteriormente pelo microrganismo, mesmo com repetidas colheitas 320 .

A proporção de portadores de cada categoria é variável e geralmente fica na dependência da precisão dos critérios utilizados e da duração do período de observação. Segundo Goldmann6, os resultados de cultura permitem detectar até $80 \%$ de portadores, a maioria de forma intermitente, e $20 \%$ a $40 \%$ permanecem colonizados por meses ou anos, freqüentemente com a mesma cepa.

O Staphylococcus aureus, enquanto um dos membros patogênicos da microbiota normal do ser humano, é encontrado em várias partes do corpo tais como fossas nasais, mãos, garganta, intestino1 7111617 , podendo ser transmitido de pessoa para pessoa (infecção cruzada), através do contato indireto (via aérea) ou por contato direto, estando esta transferência na dependência da presença de uma fonte (doentes ou portadores) 3 15. A colonização não é uniforme e distribui-se pelas diferentes partes do corpo que estão em contato com o meio externo, principalmente pele e mucosas 51318 .

Em estudos realizados com vistas a determinar a prevalência de portadores sãos desse agente no ambiente hospitalar, o pessoal de enfermagem tem sido considerado uma importante fonte do mesmo e um dos responsáveis pela sua propagação, provavelmente pelas características do seu trabalho e pelo tipo de contato mantido com os receptores da assistência prestada.

Essas considerações despertaram o interesse em conhecer o grau de colonização pelo Staphylococcus aureus e a evolução do estado de portador são em alunos de um curso de Auxiliar de Enfermagem, durante a sua formação profissional, ao serem submetidos progressivamente a influências específicas do ambiente hospitalar, em decorrência das atividades programadas e desenvolvidas nas diferentes disciplinas da grade curricular do curso.

\section{MATERIAIS E MÉTODOS}

O estudo contou com a participação de 42 alunos do Curso de Auxiliar de Enfermagem do Centro Interescolar do Hospital das Clínicas da Faculdade de Medicina de Ribeirão Preto-USP (HCFMRP-USP), que possui duração de um ano, com carga horária de 1200 horas, sendo 450 destinadas à teoria e 750 às atividades práticas.

A estrutura básica do curso é composta por disciplinas profissionalizantes e por conteúdos específicos instrumentais, em permanente relação, onde o conteúdo teórico precede a realização das atividades práticas em campos de estágio previamente selecionados.

Os alunos foram submetidos à colheita de material da cavidade nasal (N), mão direita (Md) e mão esquerda ( $\mathrm{Me}$ ) em seis diferentes momentos do desenvolvimento do curso:

primeira colheita - (em 21/02) no início do bloco teórico das disciplinas de Anatomia, Fisiologia, Microbiologia, Parasitologia e Introdução à Enfermagem, antes de serem introduzidos em atividades práticas;

segunda colheita - (em 03/05) após o bloco teórico e estágio supervisionado de Introdução à Enfermagem, em unidades de internação médico-cirúrgicas, primeiro contato com o ambiente hospitalar, onde a preocupação é o desenvolvimento de habilidades manuais e não a assunção da assistência ao paciente;

terceira colheita - (em 04/07) após a conclusão da disciplina de Enfermagem Médica, onde os alunos assumiam a assistência integral dos pacientes internados em enfermarias de Clínica Médica, Unidade de Moléstias Infectocontagiosas, Neurologia e Dermatologia ;

quarta colheita - (em 12/09) após a conclusão da disciplina de Enfermagem Cirúrgica em enfermarias de Clínica Cirúrgica, Ortopedia e no Centro Cirúrgico. Os alunos também assumiam a assistência integral do paciente, desenvolvendo todos os procedimentos necessários para esta assistência;

quinta colheita - (em 07/11) nesta colheita, 19 alunos haviam passado pelo bloco teórico e estágio de Enfermagem Pediátrica e Saúde Pública e 23 pelo de Enfermagem Obstétrica e Ginecológica e Saúde Pública, em enfermarias específicas e em ambulatórios e Unidades Básicas de Saúde da cidade. Em todos os campos, os alunos assumiam a assistência necessária aos pacientes; 
sexta colheita - (em 11/12) realizada no final do curso, após os dois grupos de alunos anteriores terem completado o rodízio das atividades descritas na quinta colheita (inversão dos alunos).

No momento das colheitas, os alunos não poderiam apresentar nenhuma lesão nas mãos e na cavidade nasal, nenhum sinal e sintoma de infecção, nem poderiam estar em esquema de antibioticoterapia.

O material foi colhido com zaragatoas estéreis, embebidas em solução salina, seguindo a seguinte técnica:

cavidade nasal - através de atrito, com movimentos circulares em ambos vestíbulos nasais, por três vezes;

mão direita e mão esquerda - friccionando, com movimentos firmes, a face interdigital dos dedos polegar e indicador de cada mão, por seis vezes.

As amostras foram encaminhadas para 0 Laboratório de Bacteriologia da FMRP-USP, no máximo duas horas após a primeira colheita, semeadas em placas de ágar-sangue e incubadas à $37^{\circ} \mathrm{C}$ por 24 horas. As colônias foram identificadas pelo aspecto e submetidas à prova da coagulase em tubo com sangue de coelho normal +EDTA a 0,1\%, para confirmação do Staphylococcus aureus.

No momento da primeira colheita foi preenchido um formulário contendo os dados de identificação do aluno e o envolvimento do mesmo com instituições de saúde, antes e/ou durante a sua formação. Essa informação foi obtida tendo em vista a possível influência do contato prévio com o ambiente hospitalar e do envolvimento com atividades assistenciais junto a pacientes internados na taxa de colonização dos alunos pelo Staphylococcus aureus. Nesse mesmo formulário foi destinado um espaço para anotação dos resultados obtidos da bacteriologia das amostras, nas diferentes colheitas.

Para efeito de análise dos dados foi elaborada uma classificação por tipo de portador de Staphylococcus aureus, adaptada de diferentes classificações utilizadas por outros autores 101219 , a saber:

não portador: o aluno que não foi colonizado pelo Staphylococcus aureus em nenhuma das áreas anatômicas e colheitas realizadas;

portador ocasional: aquele que apresentou positividade em uma ou mais das áreas anatômicas, em uma ou até duas colheitas realizadas;

portador intermitente: o aluno em que a colonização pelo Staphylococcus aureus em uma ou mais áreas anatômicas ocorreu em três ou quatro colheitas, com períodos variáveis intercalados de culturas negativas;

portador persistente: aquele aluno que apresentou positividade ao Staphylococcus aureus em cinco ou seis colheitas.

\section{RESULTADOS E DISCUSSÃO}

Do total de alunos estudados, 5 (11,9\%) foram considerados como não portadores e $37(88,1 \%)$ como portadores (Tabela 1). Apesar desse número ser inferior ao indicado na literatura, que refere uma taxa de aproximadamente $20 \%$ de não portadores, é importante considerar que as variações de positividade podem estar na dependência dos critérios e das técnicas utilizados, bem como do período de observação.

A partir dos dados da referida tabela e considerando a classificação do tipo de portador adotada pelo estudo, foi possível visualizar que $19(45,2 \%)$ alunos comportaram-se como portadores ocasionais, $12(28,6 \%)$ como intermitentes e $6(14,3 \%)$ como persistentes, demonstrando que a colonização não aumentou com o passar do tempo, como considerou o estudo de Rountree e Barbour ${ }^{14}$ que acompanhou um grupo de enfermeiras estagiárias antes, durante e após treinamento no hospital, evidenciando um aumento de $52,6 \%$ para $71,4 \%$ de portadores, após o desenvolvimento de atividades hospitalares.

A exemplo dos resultados do estudo, destacam-se aqueles encontrados nos de Hutchison et al9 e Maxwell et al12, que consideraram o tipo de contato que os participantes mantinham com o ambiente hospitalar e que também não evidenciaram aumento na taxa de portadores durante os períodos estudados.

Pela informação dos alunos sobre a atividade de trabalho desenvolvida antes e/ou durante o curso, foi possível observar que a maioria comportou-se como portadores ocasionais e intermitentes, em ambos os grupos. Tais resultados assemelham-se aos obtidos por Hutchison et al9 e Lamikanra e Olusanya 10 . A única situação em que houve maior freqüência de alunos entre os que não realizaram atividades assistenciais 
Tabela 1- Freqüência dos tipos de portadores de Staphylococcus aureus entre os 42 alunos do curso de Auxiliar de Enfermagem, segundo a atividade de trabalho com pacientes.

\begin{tabular}{|c|c|c|c|c|c|c|}
\hline \multirow[t]{2}{*}{ Tipos de portadores } & \multicolumn{2}{|c|}{ Alunos sem atividade } & \multicolumn{2}{|c|}{ Alunos com atividade } & \multicolumn{2}{|c|}{ Total } \\
\hline & $\mathrm{n}^{\circ}$ & $\%$ & $\mathrm{n}^{\circ}$ & $\%$ & $\mathrm{n}^{\circ}$ & $\%$ \\
\hline Ocasionais & 10 & 41,7 & 9 & 50,0 & 19 & 45,2 \\
\hline Intermitentes & 6 & 25,0 & 6 & 33,3 & 12 & 28,6 \\
\hline Persistentes & 4 & 16,7 & 2 & 11,1 & 6 & 14,3 \\
\hline Não portadores & 4 & 16,7 & 1 & 5,6 & 5 & 11,9 \\
\hline Total & 24 & 57,1 & 18 & 42,9 & 42 & 100,0 \\
\hline
\end{tabular}

antes e/ou durante o curso $(16,7 \%)$ em relação aos que referiram ter realizado $(11,1 \%)$, foi nos portadores persistentes.

É importante ressaltar que durante a fase de coleta de dados, 18 alunos (42,9\%) informaram que já exerciam atividades relacionadas à enfermagem, geralmente como atendentes, em instituições de saúde, antes de iniciarem o curso e/ou durante o desenvolvimento do mesmo, sendo o período de atuação bastante variado, de um mês a quinze anos. Ainda que não tenha sido possível caracterizar as condições ambientais dos serviços de saúde, $66,7 \%$ dos alunos referiram desenvolver essas atividades em hospitais gerais, não utilizados como campo de estágio pelo curso, sendo que um referiu trabalhar há dez anos e outro há quatro anos. Os demais alunos $(33,3 \%)$ referiram exercer atividades em hospital psiquiátrico, central de material, creche e unidade básica de saúde, cujas características de atendimento, aparentemente, diferem das desenvolvidas em hospitais gerais, uma vez que funcionam, quase sempre, como elo de ligação entre a organização hospitalar, o paciente e a comunidade.

Quando foi analisada a relação da colonização pelo Staphylococcus aureus nas diferentes colheitas, por área anatômica estudada, considerando ainda a atividade de trabalho desenvolvida pelos alunos (Tabela 2), observouse, em ambos os momentos, uma maior freqüência de colonização na cavidade nasal, confirmando que a mesma tem sido a área anatômica mais freqüentemente positiva e que, na maioria dos adultos, a colonização nasal é que garante a colonização da superfície cutânea16 19 .

Tabela 2- Freqüência das amostras positivas para o Staphylococcus aureus nos alunos do curso de Auxiliar de Enfermagem, por colheita realizada, atividade de trabalho e area anatômica examinada.

\begin{tabular}{|c|c|c|c|c|c|c|}
\hline \multirow[t]{2}{*}{ Colheitas } & \multicolumn{3}{|c|}{ Alunos sem atividade } & \multicolumn{3}{|c|}{ Alunos com atividade } \\
\hline & $\mathrm{N}$ & $\mathrm{Md}$ & $\mathrm{Me}$ & $\mathrm{N}$ & $\mathrm{Md}$ & $\mathrm{Me}$ \\
\hline $1^{\mathrm{a}}$ & 10 & 5 & 5 & 9 & 6 & 5 \\
\hline $2^{\mathrm{a}}$ & 7 & 4 & 4 & 5 & 2 & 2 \\
\hline $3^{\text {a }}$ & 11 & 8 & 7 & 8 & 7 & 7 \\
\hline $4^{\mathrm{a}}$ & 13 & 7 & 6 & 8 & 6 & 6 \\
\hline $5^{\mathrm{a}}$ & 5 & 2 & 4 & 4 & 1 & 2 \\
\hline $6^{\underline{a}}$ & 6 & 4 & 4 & 4 & 2 & 1 \\
\hline Total & $52(46,4 \%)$ & $30(26,8 \%)$ & $30(26,8 \%)$ & $38(44,7 \%)$ & $24(28,2 \%)$ & $23(27,1 \%)$ \\
\hline
\end{tabular}

$\mathrm{N}$ = cavidade nasal; $\mathrm{Md}=$ mão direita; $\mathrm{Me}=$ mão esquerda.

Outra observação é que houve uma variação nas taxas de positividade nas diferentes áreas anatômicas e colheitas realizadas, cujos resultados não evidenciaram diferença entre os que exerceram atividades assistenciais em serviços de saúde e os que não as exerceram. A análise dessas variações fica difícil de ser realizada, considerando que durante a obtenção das amostras, mesmo que em momentos diferentes, alguns alunos poderiam ter se comportado como portadores intermitentes ou ocasionais, não estando colonizados no momento da colheita.

A evolução do estado de portador são de Staphylococcus aureus nos 37 alunos portadores, a partir das colheitas realizadas, encontra-se na 
Tabela 3. Nos $22(59,5 \%)$ alunos que se mostraram colonizados pelo Staphylococcus aureus em uma ou mais áreas anatômicas, a partir da primeira colheita, $11(50,0 \%)$ comportaram-se como portadores intermitentes, 6 (27,3\%) como persistentes e $5(22,7 \%)$ como ocasionais, sendo que a metade dos alunos referiu ter exercido atividades assistenciais antes e/ou durante o curso. Dentre os seis alunos que se comportaram como portadores persistentes, três mostraramse colonizados em, praticamente, todas as áreas anatômicas, durante todo o período de observação.

O único aluno portador são a partir da segunda colheita, caracterizou-se como portador intermitente uma vez que apresentou colonização pelo Staphylococcus aureus na cavidade nasal e/ou mão direita e esquerda, em intervalos variáveis durante as colheitas. Esse aluno informou não ter desenvolvido atividade assistencial antes e/ou durante o desenvolvimento do Curso de Auxiliar de Enfermagem.

Todos os $12(32,4 \%)$ alunos portadores do Staphylococcus aureus em uma ou mais áreas anatômicas, a partir das terceira e quarta colheitas, comportaram-se como portadores ocasionais. Do total dos que fizeram parte do primeiro grupo, $5(83,3 \%)$ apresentaram positividade em uma ou mais áreas anatômicas, em até duas colheitas realizadas e um aluno

Tabela 3- Evolução do estado de portador são de Staphylococcus aureus nos alunos do curso de Auxiliar de Enfermagem, a partir das colheitas realizadas

\begin{tabular}{|c|c|c|c|c|c|}
\hline \multirow[t]{2}{*}{ Colheitas } & \multirow[t]{2}{*}{ Portadores ocasionais } & \multirow[t]{2}{*}{ Portadores intermitentes } & \multirow[t]{2}{*}{ Portadores persistentes } & \multicolumn{2}{|c|}{ Total } \\
\hline & & & & $\mathrm{n}^{0}$ & $\%$ \\
\hline $1^{\underline{a}}$ & 5 & 11 & 6 & 22 & 59,5 \\
\hline $2^{\underline{a}}$ & - & 1 & - & 1 & 2,7 \\
\hline $3^{\underline{a}}$ & 6 & - & - & 6 & 16,2 \\
\hline $4^{-a}$ & 6 & - & - & 6 & 16,2 \\
\hline $5^{\underline{a}}$ & 1 & - & - & 1 & 2,7 \\
\hline $6^{\mathrm{a}}$ & 1 & - & - & 1 & 2,7 \\
\hline Total & $19(51,4)$ & $12(32,4)$ & $6(16,2)$ & 37 & 100,0 \\
\hline
\end{tabular}

$(16,7 \%)$ apresentou-se colonizado em apenas uma área anatômica em uma colheita realizada. Apenas um aluno referiu ter desenvolvido atividades assistenciais antes e/ou durante o curso. Dentre os do segundo grupo, a cavidade nasal de um mesmo aluno foi a única área anatômica colonizada em colheitas sucessivas. Dos alunos desse grupo, 4 (66,7\%) já trabalhavam em serviços de saúde.

Considerando as classificações dos tipos de portadores adotadas no estudo, para as quais portador ocasional é aquele que apresenta positividade em uma ou mais das áreas anatômicas, em uma ou até duas colheitas realizadas, os dois alunos que estiveram colonizados pelo Staphylococcus aureus a partir da quinta e sexta colheitas, só poderiam comportar-se como portadores ocasionais. Esses alunos foram colonizados apenas na cavidade nasal, em uma única colheita.

\section{REFERÊNCIAS BIBLIOGRÁFICAS}

1. Adams BC, Marrie TJ. Hand carriage of aerobic gramnegative rods may not be transient. Journal Hygiene 89:33-46, 1982

2. Anderson GW, Arnstein MG, Lester MR. Infecciones por estafilococo. In: Anderson GW, Arnstein MG, Lester MR (eds) Control de enfermidades transmissibles, $4^{\text {a }}$ edição, Interamericana, México, p.330-339, 1965.

3. Davis BD, Dulbecco R, Eisen HN, Ginsberg HS, Wood WB. Relações hospedeiro-parasita nas doenças bacterianas. In: Davis BD, Dulbecco R, Eisen HN,
Ginsberg HS, Wood WB (eds) Microbiologia, Edart, São Paulo, p.9-54, 1973.

4. Forattini OP. As doenças transmissíveis. In: Forattini OP (ed) Epidemiologia geral, Edgard Blucher Ltda, São Paulo, p.191-206, 1986.

5. Gilbert P. Principles of microbiol pathogenicity and epidemiology. In: Hugo WB, Russel AD (eds) Pharmaceutical microbiology, $5^{\underline{a}}$ edição, Blackwell Scientific, London, p. 82-96, 1992. 
6. Goldmann DA. Epidemiology of Staphylococcus aureus and Group-A streptococci. In: Bennett JV, Brachman PS (eds) Hospital infections, Brown Little, Boston, p.767787, 1992.

7. Gould D. Nurses' hands as vectors of hospital-acquired infection: a review. Journal of Advanced Nursing 16:1216-1225, 1991

8. Heczko PB, Bullanda M, Hoeffler U. Nasal carriage of Staphylococcus aureus and its influence on hospital infections caused by methicillin resistant strains. Journal of Medical Microbiology 274:333-341, 1990.

9. Hutchison JGP, Green C, Grimson TA. Nasal carriage of Staphylococcus aureus in nurses. Journal of Clinical Pathology 10:92-95, 1957.

10. Lamikanra A, Olusanya Ol. A long-term study of the nasal carriage of Staphylococcus aureus in the healthy nigerian students. Transactions of the Royal Society of Tropical Medicine and Hygiene 82:500-502, 1988.

11. Levy CE, Costa JC, Lama J, Furlan MLS, Toloy RC, Pasti MJ, Takeda E. Papel epidemiológico das mãos nas infecções hospitalares. Revista da Sociedade Brasileira de Medicina Tropical 21:89, 1988.

12. Maxwell JG, Ford CR, Peterson DE, Mitchell CR. Longterm study of nasal staphylococci among hospital personal. American Journal of Surgery 118:849-854, 1969.

13. Noble WC. Microbiology of normal skin. In: Noble WC (ed) Microbial skin disease: its epidemiology, Edward Arnold, London, p. 4 -23, 1983.
14. Rountree PM, Barbour RGH. Nasal carrier rate of Staphylococcus aureus pyogenes in hospital nurses. Journal of Pathology and Bacteriology 63:313-324, 1951.

15. Rouquayrol MZ, Veras FMF. Doenças transmissíveis e modos de transmissão. In: Rouquayrol MZ (ed) Epidemiologia e saúde, 4⿳a edição, MEDSI-Editora Médica e Científica, Rio de Janeiro, p.217-268, 1994.

16. Santos BMO, Aguillar OM, Takakura MS. Colonização simultânea de Staphylococcus aureus na cavidade nasal e mãos de portadores sãos de um hospital escola. Revista de Microbiologia 21:309-314, 1990.

17. Santos BMO, Scochi CGS, Garcia e Souza MT. Prevalência de portadores sãos de Staphylococcus aureus em pessoal de enfermagem de unidades pediátricas de um hospital geral escola. Parte I. Revista Paulista de Hospitais 38:24-29, 1990.

18. Trabulsi LR, Toledo MRF. Flora normal do corpo humano. In: Trabulsi LR (ed) Microbiologia, $2^{a}$ edição, Atheneu, Rio de Janeiro, p. 43-46, 1989.

19. Williams REO. Healthy carriage of Staphylococcus aureus: its prevalence and importance. Bacteriological Reviews 27:56-71, 1963.

20. Zierdt $\mathrm{CH}$. Long term Staphylococcus aureus carrier state in hospital patients. Journal of Clinical Microbiology 16:517-520, 1982. 